\title{
Single-Molecule Junctions with Highly Improved Stability
}

\author{
Xinlei Yao ${ }^{\text {a }}$, Maxime Vonesch ${ }^{\mathrm{b}}$, Mä̈wenn Combes ${ }^{\mathrm{b}}$, Jean Weiss ${ }^{\mathrm{b}}$, Xiaonan Sun ${ }^{\mathrm{a} *}$, and Jean-Christophe La- \\ croix $^{\text {a* }}$ \\ a Université de Paris, ITODYS, CNRS-UMR 7086, 15 rue Jean-Antoine de Baif, 75205 Paris Cedex 13, France \\ ${ }^{\mathrm{b}}$ Institut de Chimie de Strasbourg, CNRS-UMR 7177, Université de Strasbourg, 4 rue Blaise Pascal, 670oo Strasbourg, France \\ Supporting Information Placeholder
}

\begin{abstract}
Single-molecule junctions (SMJs) have been fabricated using layers generated by diazonium electroreduction. This process immobilizes the molecule and creates a direct C-Au covalent bond between the molecule and the electrode. As a result, rigid oligomers of variable length, mainly perpendicular to the surface, are formed. The oligomers are based on porphyrin derivatives in their free base or cobalt complex forms. The conductance of the grafted oligomers has been studied by means of the scanning-tunneling-microscopy break-junction (STM-bj) technique and $\mathrm{G}(\mathrm{t})$ measurements, and the lifetime of the single-molecule junctions has been investigated. The conductance histograms indicate that charge transport in the porphyrins is relatively efficient and influenced by the presence of the cobalt center. With both systems, random telegraph $G(t)$ signals are easily recorded showing SMJ on off states. The SMJs then stabilize and exhibit a surprisingly long lifetime around to s, and attenuation plots, obtained by both $\mathrm{G}(\mathrm{t})$ and STM-bj conductance measurements, give identical attenuation values. This work shows that highly stable SMJs can be prepared using diazonium grafting approach.
\end{abstract}

KEYWORDS: diazonium electroreduction, single-molecule junctions, molecular electronics, tunneling, hopping

Organic and molecular electronics are scientific domains aiming at developing lower-cost materials, processes and devices for information technologies. Whereas organic electronics have already a significant impact on the market, with the commercialization of display technologies based on organic light-emitting diodes, ${ }^{2}$ molecular electronics have an obvious potential for extreme miniaturization, but the production and the commercialization of devices is hindered by several key issues, such as robustness, reliability, fabrication yield and reproducibility.

The molecular junction (MJ) is the basic component of molecular electronics, and consists of an assembly of many molecules or a single molecule between two conducting electrodes.3-7 Large-area molecular junctions are usually stable and reproducible. ${ }^{6,7,8-11}$ Fabrication consists of the deposition of a molecular layer on a bottom electrode and the subsequent deposition of a top contact electrode. ${ }^{12,13,14}$ It is possible to record $\mathrm{I}(\mathrm{V})$ curves at various film thicknesses and temperatures, to obtain an attenuation plot (slope $\beta$ ) vs. junction length and to study the dominant transport mechanism. ${ }^{10,15-17}$ Production yield can be high and, when robust multifunctional layers based on diazonium electroreduction are used, the top contact electrode can be deposited by direct evapora- tion. Since large-area MJs are stable, many important results, leading to a better understanding of transport mechanisms, have been reported. ${ }^{18-23}$ However, such systems, need to be shrunk to a few molecules or to the single-molecule level to make molecular electronics highly valuable.

Single-molecule junctions (SMJs), ${ }^{24,25}$ are less stable and are technically more challenging. They are fabricated mainly by two techniques, i.e. scanning-tunneling microscopy break junction (STM-bj).26-31 or mechanically controlled breakjunction (MCBJ), 32-36 and graphene-based SMJs have also recently appeared in the litterature. 37-39 In most STM-bj experiments, the conductance is continuously recorded as an atomic contact is broken in a solution of molecules, and a conductance plateau, indicating the formation of a SMJ, is observed when a molecule comes between the two electrodes during the pulling process. The Au tip is further stretched into a thin gold wire and finally breaks. As a result, the lifetime of SMJs fabricated by the STM-bj technique is short. SMJs have been constructed using different families of molecular building blocks, $4^{0-46}$ and various anchoring groups, 31,47,48 and were recently combined with sophisticated switchable functionalities. ${ }^{4-51}$ Transport in these SMJs is highly versatile to the variation of different factors, whereas the instability largely limits a deeper investigation of their com- 
plex transport and electronic properties. Consequently, one of the major challenges in molecular electronics is to optimize SMJs in terms of both charge transport and lifetime for the development and fabrication of real-life molecular devices.

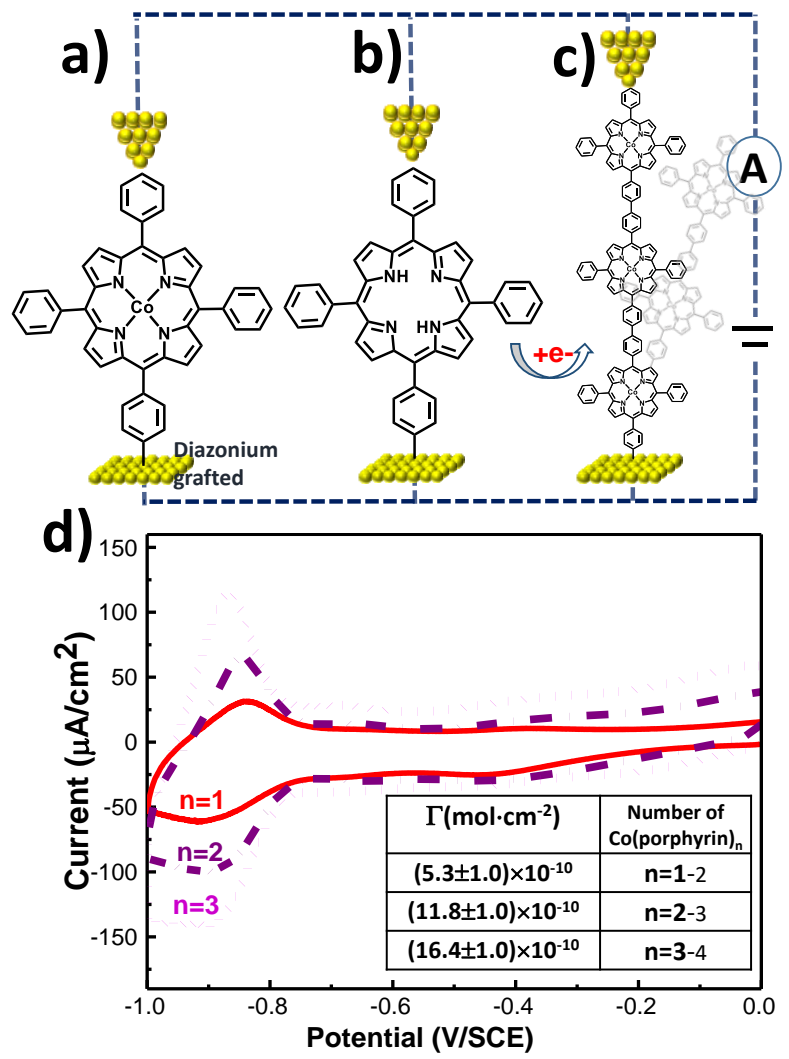

Figure 1. Diazonium-based porphyrin SMJs: (a, b, c) Scheme of $\mathrm{Au}-[\mathrm{MTPP}]_{\mathrm{n}}$-Au SMJs where $\mathrm{M}$ is cobalt or $\mathrm{H}_{2}$ and $\mathrm{n}=1 \sim 3$; (d) electroactivity (CV) of CoTPP layers with different thickness in o.1 $\mathrm{M}$ solution of $\mathrm{tBuNPF}_{6}$ in acetonitrile with scan rate $0.1{\mathrm{~V} . \mathrm{s}^{-1}}^{-}$

This work describes highly stable SMJs prepared using layers generated by diazonium electroreduction. 52-54 The oligomers are based on porphyrin derivatives in their free base or cobalt complex forms; these are promising building blocks for molecular devices (Figure 1). The conductance of the oligomers is studied by the STM-bj technique, while the lifetime of the SMJs generated are investigated by conductance vs. time $(G(t))$ measurements. The SMJs have very long lifetimes, around $10 \mathrm{~s}$, and signal/noise ratios above 10 are observed. Plots of the attenuation of conductance with increasing junction length, obtained by both $\mathrm{G}(\mathrm{t})$ and STM-bj measurements, give similar results for the attenuation factor, which is smaller in the porphyrin-metal complexes than in those of the free base.

The free base, amino-tetraphenyl-porphyrin $\mathrm{H}_{2} \mathrm{TPP}-\mathrm{NH}_{2}$ and its corresponding Co complex, CoTPP- $\mathrm{NH}_{2}$, were synthesized using previously reported procedures. $555^{6}$ The two molecules have the same length $(1.8 \mathrm{~nm})$ but differ in the presence or the absence of the cobalt metal center. The amino terminal group acts as an electroactive precursor for diazonium grafting onto the bottom electrode. The electrochemical properties of $\mathrm{H}_{2}$ TPP- $\mathrm{NH}_{2}$ and CoTPP- $\mathrm{NH}_{2}$ in solution are described in the Supporting Information. Briefly, CoTPP-NH $\mathrm{H}_{2}$ shows (Figure Sia) four reversible signals at $0.75,-0.86,-1.20$ and -1.59 V/SCE, attributed to $\mathrm{Co}(\mathrm{III}) / \mathrm{Co}(\mathrm{II}), \mathrm{Co}(\mathrm{II}) / \mathrm{Co}(\mathrm{I})$ and the porphyrin core (two signal), respectively, and an irreversible peak for amine oxidation at 1 V/SCE. $\mathrm{H}_{2}$ TPP- $\mathrm{NH}_{2}$ shows (Figure $\mathrm{S} 1 \mathrm{~b}$ ) the two reversible signals of the porphyrin subunit at -1.14 and $-1.53 \mathrm{~V} / \mathrm{SCE}$ and an irreversible peak for amine oxidation around $1 \mathrm{~V} / \mathrm{SCE}$. These results indicate that the HOMO and LUMO of CoTPP- $\mathrm{NH}_{2}$ are centered on the cobalt atom and are completely different from those of the free porphyrin base. The HOMO of CoTPP core is much closer to the Fermi level of the bottom gold electrode than that of the free base.

The porphyrins were grafted, as free base or metal complexes, with thickness control on flat gold substrates deposited on $\mathrm{Si} / \mathrm{SiO}_{2}$ wafers. The diazonium derivatives of the aminoporphyrin derivatives were generated in-situ following an already published procedure.57 and were then reduced by sweeping the potential of the gold electrode between $0.5 \mathrm{~V}$ or o.1 V/SCE and various final potentials for a variable number of scans (Table $\mathrm{S}_{1}$ ). During the first cycle, an irreversible peak close to o V/SCE, characteristic of diazonium reduction, is observed. In the next cycles, the cyclic voltammograms (CVs) show a current decrease, and the diazonium reduction peak almost disappears after a few cycles, indicating that oligoporphyrins have been grafted onto the surface. ${ }^{17,54,57-59}$ Ultrathin modified films are thus obtained, as confirmed by thickness measurements by the AFM scratching technique 6o (see Figure $\mathrm{S}_{2}$ and $\mathrm{S}_{3}$ ). Films with thicknesses between 2 and $5 \pm 1 \mathrm{~nm}$, i.e. consisting of $n$-mers with $n=1,2$ or 3 , were thus generated; the roughness was close to $1 \mathrm{~nm}$. The $[\text { CoTPP }]_{\mathrm{n}}$-modified electrode was also studied by cyclic voltammetry focused on the reduction of $\mathrm{CoTPP}^{2+}$. The CV curve in Figure 1a shows the expected reversible reduction wave at $\mathrm{E}_{1 / 2}=-0.9 \mathrm{~V}\left(\Delta \mathrm{E}_{\mathrm{p}} \approx\right.$ $\mathrm{o} V$ at low scan rates). The shape of this signal is characteristic of immobilized electroactive species. The film deposited is very stable and can be reversibly swept without any loss of the $\mathrm{CoTPP}^{2+} /+$ signal. Integration of the redox peaks yields an apparent surface concentration which depends on the electrochemical conditions used for grafting. Assuming a surface concentration of $5 \times 10^{-10} \mathrm{~mol} \cdot \mathrm{cm}^{-2}$ for a monolayer, ${ }^{61}$ the surface concentrations for the three films displayed in Figure $1 \mathrm{~b}$ are $5.3 \times 10^{-10}, 11.8 \times 10^{-10}$ and $16.4 \pm 1 \times 10^{-10} \mathrm{~mol} \cdot \mathrm{cm}^{-2}$ and correspond to measured thicknesses of $2.5,3.2$ and $4.8 \pm 1 \mathrm{~nm}$, respectively. 

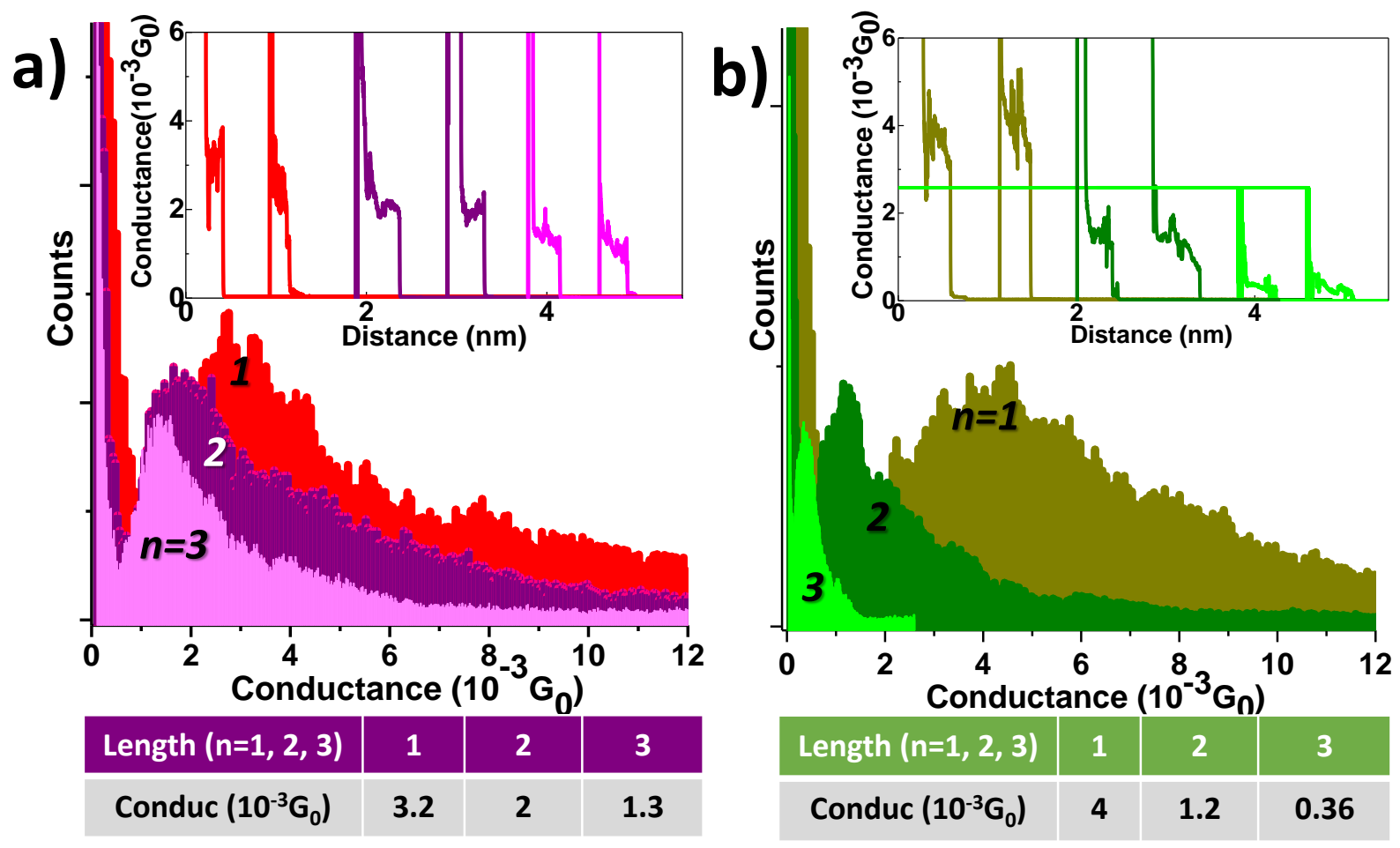

Figure 2. Combined STM-bj histograms of Conductance vs. length plots from Au-[MTPP $]_{n}-A u$ SMJs, $n=1 \sim 3$. (a) Au-[CoTPP $]_{n}-A u$, $\mathrm{V}_{\text {bias }}=50 \mathrm{mV}$; (b) Au-[TPP]n-Au, $\mathrm{V}_{\text {bias }}=50 \mathrm{mV}$.

The surface concentration and the thicknesses are in good agreement (Inset in Figure 2 and Table 1 in SI) thus indicating that the grafted films are based on n-mers of [CoTTP] with $\mathrm{n}=1$ (monolayer), 2 and 3 .

Since it is usually difficult, using diazonium electroreduction, to restrict the growth to a precise number of layers on the whole surface, the average thickness measured by AFM on a $2 \times 2 \mu \mathrm{m}^{2}$ area provides only the most probable number of monomers in the oligomers. For this reason, two possible for the numbers of porphyrins are given in the Table inset of Figure $\mathrm{lb}$. Moreover, once a monolayer is grafted, the deposition of the next layers can generate moderate roughness, ${ }^{62}$ as illustrated in Figure ic with films of Next, the STM-bj technique was used to build Au-molecule-Au junctions. Contrary to most of the STM-bj results already published, the target molecules are immobilized on the Au bottom electrode in a compact layer and cannot leave the substrate or move easily inside the layer. SMJs have already been formed from highly compact grafted films generated from diazonium electroreduction. ${ }^{29,46}$ from thiols layers ${ }^{51}$ or from self-assembled monolayers with terminal alkyne contact groups 63,64 absorbed on a $\mathrm{Si}$ or Au surface. Self-assembled monolayers with molecules flat on the surface have also been used in this case a flat-lying single molecule is picked up to form a SMJ. ${ }^{65}$ This is not the case in the present study as the molecules are mainly perpendicular to the surface in the films. ${ }^{53}$ The gold STM tip was mechanically driven into contact with the molecules on the bottom electrode and was then pulled out to generate SMJs. The conductance vs. distance $(G(d))$ traces show current plateaus, which clearly indicate that a single molecule bridges the gap between the two electrodes and that Au-[MTPP $]_{n}-A u(n=1,2,3)$ SMJs are formed. Typical traces with current plateaus which clearly indicate that a single molecule bridges the gap between the two electrodes and that $\mathrm{Au}-[\mathrm{MTPP}]_{\mathrm{n}}-\mathrm{Au}(\mathrm{n}=1,2,3)$ SMJs are formed. Typical traces with current plateaus are shown (Figures $2 \mathrm{a}$ and $2 \mathrm{~b}$ ) with plateau lengths from $3 \AA$ to $1 \mathrm{~nm}$. (more $\mathrm{G}(\mathrm{d})$ traces showing plateaus are given in the SI file). The conductance of the junctions is determined by twodimensional $(2 \mathrm{D})$ histograms constructed from hundreds of G(d) traces with visible current plateaus. ${ }^{66,67}$ Only single peaks were observed for all the histograms that are due to the simple Au-phenyl terminal group contact configuration. 50,68-72 The conductance value obtained from the STM-bj measurement is defined as $\mathrm{G}_{\text {Histo }}$ hereafter and is a averaged value for many different SMJs. 


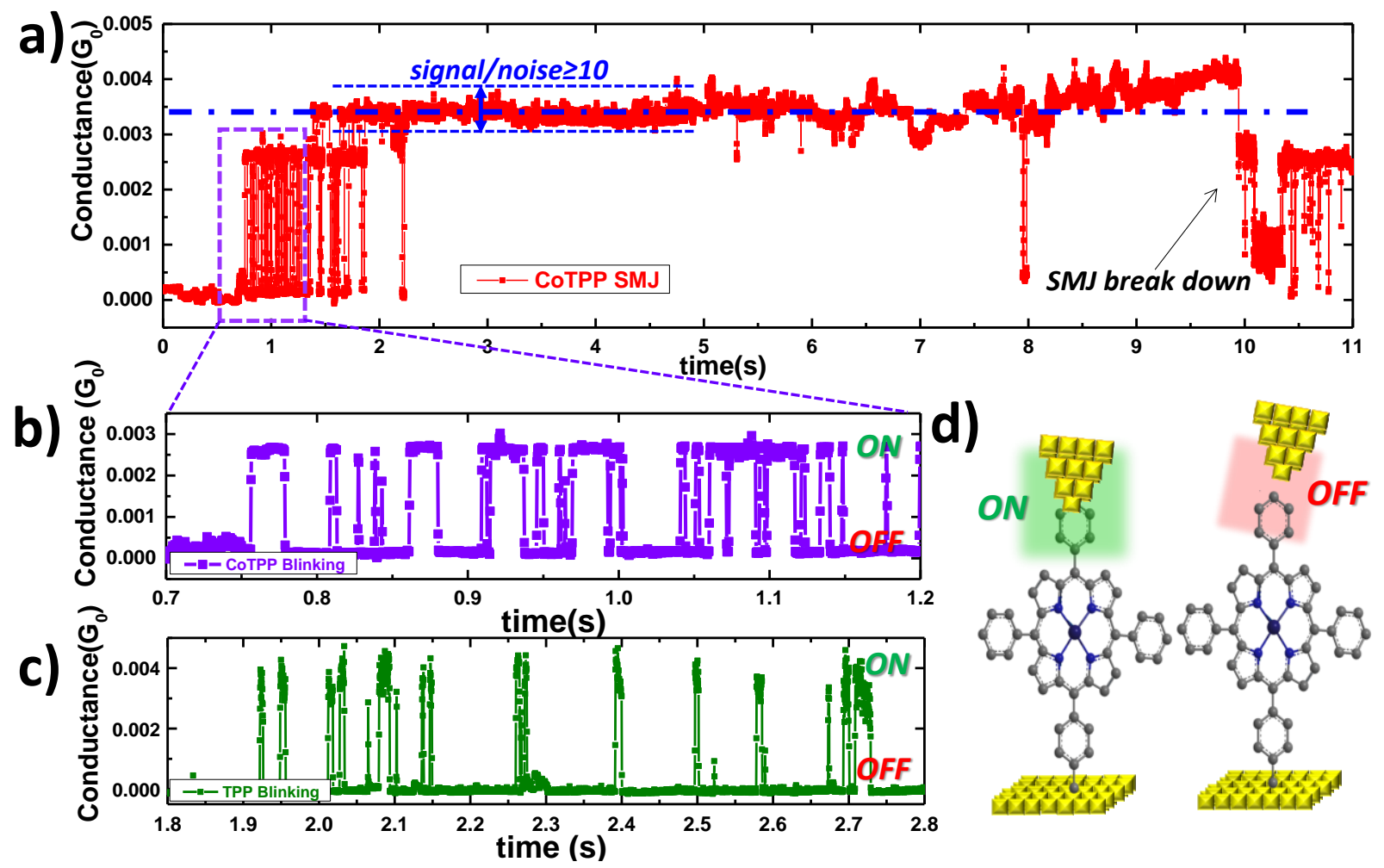

Figure 3. Conductance vs. time traces from Au-[CoTPP]-Au junction (a) G(t) trace showing initial blinking and subsequent stabilization of the SMJ. (b) Zoom in the first second of SMJ formation showing random telegraph signals. (c) Au-[TPP]-Au junction telegraph signals (d) Scheme showing the SMJ ON (tip is in contact with the molecule) and OFF (tip is not in contact with the molecule) states.

Three Au-[CoTPP $]_{\mathrm{n}}$-Au SMJs with different lengths, varying from about $1.8(\mathrm{n}=1)$ to $5(\mathrm{n}=3) \mathrm{nm}$, were studied. Typical plateaus are displayed and combined conductance histograms for the three systems are shown in Figure 2a. The conductance values $\left(\mathrm{G}_{\mathrm{Histo}}\right)$ of the SMJs are around $3.2 \times 10^{-3}$ $\mathrm{G}_{0}, 2 \times 10^{-3} \mathrm{G}_{0}$ and decrease to $1.3 \times 10^{-3} \mathrm{G}_{\mathrm{o}}$ as shown in the table in Figure 2a. The Au-[CoTPP $]_{\mathrm{n}}-\mathrm{Au} \mathrm{SMJs}$ transport charge efficiently, have rather high conductance values $\left(10^{-3} G_{0}\right)$ and fall relatively slowly as the junction length increases.

$\mathrm{Au}-[\mathrm{TPP}]_{\mathrm{n}}-\mathrm{Au} \mathrm{SMJs}$, formed with free base $[\mathrm{TPP}]_{\mathrm{n}}$ oligomers having exactly the same configurations and contact groups as $\mathrm{Au}-[\mathrm{CoTPP}]_{\mathrm{n}}-\mathrm{Au} \mathrm{SMJs}$ were also studied. It is interesting to compare the transport behaviors of the two different types of SMJs, as any difference can be clearly attributed to the metal. Conductance vs. distance $(\mathrm{G}(\mathrm{d}))$ traces, showing plateaus, are displayed in Figure $2 \mathrm{~b}$. As already observed, the conductance of the Au-[TPP $]_{1}-A u$ SMJ is slightly higher $\left(4 \times 10^{-3} G_{0}\right)$ than that of the Au-[CoTPP $]_{1}-A u$ SMJ $\left(3 \times 10^{-3} G_{0}\right) .44,45,73^{-75}$ However, the $\mathrm{Au}-[\mathrm{TPP}]_{\mathrm{n}}-\mathrm{Au} \mathrm{SMJs}$ show a stronger dependence on the number of monomers in the junction. Combined conductance histograms for the three $\mathrm{Au}-[\mathrm{TPP}]_{\mathrm{n}}-\mathrm{Au}(\mathrm{n}=1-3)$ SMJs are also shown in Figure $2 \mathrm{~b}$. The conductance values are around $4 \times 10^{-3} G_{0}, 1.2 \times 10^{-3} G_{0}$ and $3.6 \times 10^{-4} G_{o}$ (table in Figure $2 b$ ). The $\mathrm{Au}-[\mathrm{TPP}]_{\mathrm{n}}-\mathrm{Au} \mathrm{SMJs}$, without a coordinated metal center, transport charges less efficiently and show a rather fast decay of their conductance (one order of a magnitude from $10^{-3}$ to $10^{-4} G_{0}$ ) as the junction length increases. This indicates that the metal has a strong impact on the conductance of the SMJs and reflects the fact that the HOMO and LUMO of [CoTPP $]_{n}$ are closer to the Fermi level of the gold than those of - $[\mathrm{TPP}]_{\mathrm{n}}$ in agreement with the electrochemical results.

The advantage of using diazonium reduction to prepare SMJs is that the oligomers are covalently bonded, which impedes molecular motion. This could help to improve junction stability. STM conductance vs. time $(\mathrm{G}(\mathrm{t}))$ measurements were therefore performed. This technique has been previously used, mainly in MCBJ configurations, to demonstrate the formation of SMJs, and characterizes both the SMJ conductance and the lifetime of the junction. ${ }^{29,38,39,50,73,76,77,78}$

In such experiments, often referred to as SMJ blinking in previous work; the conductance blinks between two different values, one corresponding to a situation where no molecule bridges the two electrodes and another where an SMJ is formed. As a consequence, the $\mathrm{G}(\mathrm{t})$ curve shows random telegraph signals.

To perform such experiments, the STM tip was stabilized at a fixed distance set according to the initial tunneling parameters $\left(\mathrm{I}_{\mathrm{t}}=1 \mathrm{nA}\right.$, and $\mathrm{U}_{\mathrm{s}}=0.05 \mathrm{~V}$ are used here). These parameters are chosen so that the tip is almost in contact with the layer. The STM feedback is then turned off and the base cur- 
rent is recorded when no molecule bridges the two electrodes. Due to thermal or mechanical drift, the tip comes into contact with the layer and the conductance suddenly increases once a junction is formed, meaning that one or several molecules bridge(s) the two electrodes. All the G(t) curves reported here are shown as untreated raw data.

The gold electrode modified by a monolayer of CoTPP was first studied. The measured current, converted into conductance values and recorded as a function of time, is shown in Figure 3. A conductance blinking series is recorded from the STM G(t) curve at the initial state of MJ formation (shown in Figures $3 \mathrm{a}$ and $\mathrm{b}$ ). This indicates that a single molecule is trapped between the two electrodes79,80 for a short time (less than $0.1 \mathrm{~s}$ ), where a plateau of the conductance is observed at $2.7 \times 10^{-3} \mathrm{G}_{\mathrm{o}}$ (corresponding to the SMJ ON state). The conductance value is coherent with those observed in the STM-bj current histograms, which again confirms that only one molecule bridges the two electrodes. After a very short time, the contact between the molecule and the tip is broken, and the conductance jumps back to the tunneling current level (SMJ OFF state). The SMJs are repeatedly formed and broken sequentially without any modulation of the tip surface distance (different from the STM-bj G(d) measurements). As a result, a random telegraph signals is observed in Figures $3 b$, where the SMJ ON and OFF states alternate. Similar telegraph $G(t)$ signals are also recorded form the freebase Au-[TPP]-Au SMJ in Figure $3 c$ which the ON/OFF signals alternate at different frequencies. Note that the blinking lasts, in the present SMJ formation, for $2 \mathrm{~s}$ which was reported mainly when using the mechanically controlled break junction (MCBJ) techniques, due to a known higher stability. 35,36,38,81

Next, the frequency of the SMJ blinking decreases, showing that the SMJ ON state tends to stabilize. After $2 \mathrm{~s}$ the conductance stops blinking and a very stable SMJ is formed with a conductance close to $3.3 \times 10^{-3} \mathrm{G}_{\mathrm{o}}$ and a lifetime as long as $8 \mathrm{~s}$ before the junction breaks down again (Figure $3 \mathrm{a}$ ). The timeaverage value of the conductance for a single SMJ calculated from the stabilized $G(t)$ curves is defined as $G_{\text {Time. }} G_{\text {Time }}$ is again coherent with $\mathrm{G}_{\text {Histo }}$ observed in the STM-bj current histograms but is slightly higher than the conductance of the ON states $\left(2.7 \times 10^{-3} G_{0}\right)$ found from the telegraph $G(t)$ signals. Interpretation of these two values is beyond the scope of this study. Note also that the signal-to-noise ratio in the $G(t)$ curves, defined by the central conductance value divided by the maximum conductance fluctuation, is higher than 10. This is better than in most SMJ blinking experiments previously reported, 75-77 and is close to the best value from the MCBJ experiments, 38 and the very recent result by DiezPerez. ${ }^{29}$

Similar G(t) measurements with junctions of different lengths were performed on Au-[CoTPP $]_{n}$ layers with $\mathrm{n}=2$ and 3, and on $\mathrm{Au}-[\mathrm{TPP}]_{\mathrm{n}}$ layers with $\mathrm{n}=1$ and 2 . Figure 4 shows the dif- ferent $G(t)$ curves from the Au-[CoTPP $]_{n}-A u(n=1,2,3)$ SMJs measured with recording time of $3 \mathrm{~s}$. The conductance values are first close to zero as the SMJs are not yet formed but further jump, blink (see SI files for detailed blinking curves) and stabilize for a few seconds at $\mathrm{G}_{\text {Time }}$ values of $3.2 \times 10^{-3} \mathrm{G}_{0}, 2 \times 10^{-3}$ $\mathrm{G}_{\mathrm{o}}$ and $1.2 \times 10^{-3} \mathrm{G}_{\mathrm{o}}$ for $\mathrm{n}=1,2$ and 3, respectively. A small, nonlinear decay of the conductance is thus observed as the $[\text { CoTPP }]_{n}$ thickness increases. The $\mathrm{G}(\mathrm{t})$ conductance values for different lengths are in particularly good agreement with those observed from the STM-bj G(d) histograms in Figure 2a. Figure SI6 shows similar $G(t)$ curves for $A u-[T P P]_{n}-A u$ SMJs with $\mathrm{n}=\mathbf{1}$ and 2 . Here again the conductance values obtained from the $\mathrm{G}(\mathrm{t})$ experiments are in good agreement with the results of STM-bj measurements.

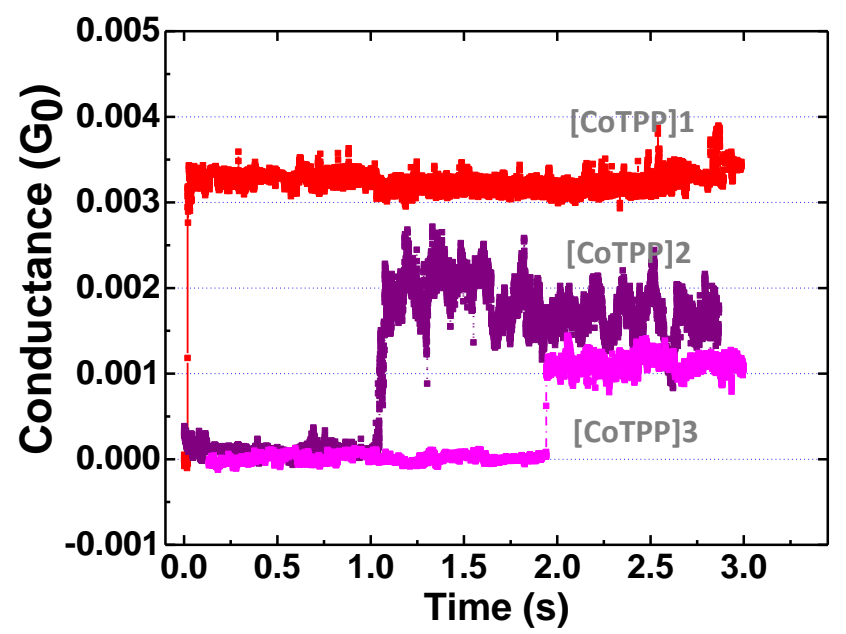

Figure 4. Conductance vs. time traces from Au-[CoTPP]n-Au junctions $(\mathrm{n}=1,2,3)$

It is important to note that SMJs fabricated with these molecular systems can easily have lifetimes as long as several seconds. We attribute this improvement to the advantages of the diazonium electroreduction grafting, i.e. the oligomers are covalently bonded to the bottom electrode in a highly compact and robust film which impedes molecular motion. Moreover, the conductance values $\mathrm{G}_{\mathrm{Histo}}$ and $\mathrm{G}_{\text {Time }}$ are measured from two different methods of SMJ formation and characterization. The $\mathrm{G}_{\text {Histo }}$ value is an average conductance value extracted from hundreds or thousands of $G(d)$ traces using the STM-bj technique. It represents a statistical conductance value from many different SMJs just after they are generated.

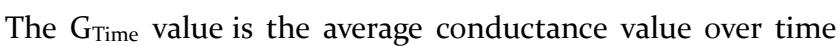
(lifetime always above $1 \mathrm{~s}$ in our experiments) obtained directly from one stabilized SMJ. These two average values may differ significantly ${ }^{82}$ if the configurations and the coupling between the molecule and the electrodes during the STM-bj pulling process are different from those obtained after stabilization of the SMJ. However, in the present case, the $\mathrm{G}_{\text {Histo }}$ and the $\mathrm{G}_{\text {Time }}$ values agree well for two different molecules and for several n-mers. This is very first time that such agreement is 
observed, (i) confirming the reliability of the SMJ conductance measurements and (ii) indicating that both methods provide reliable and factual measurements.
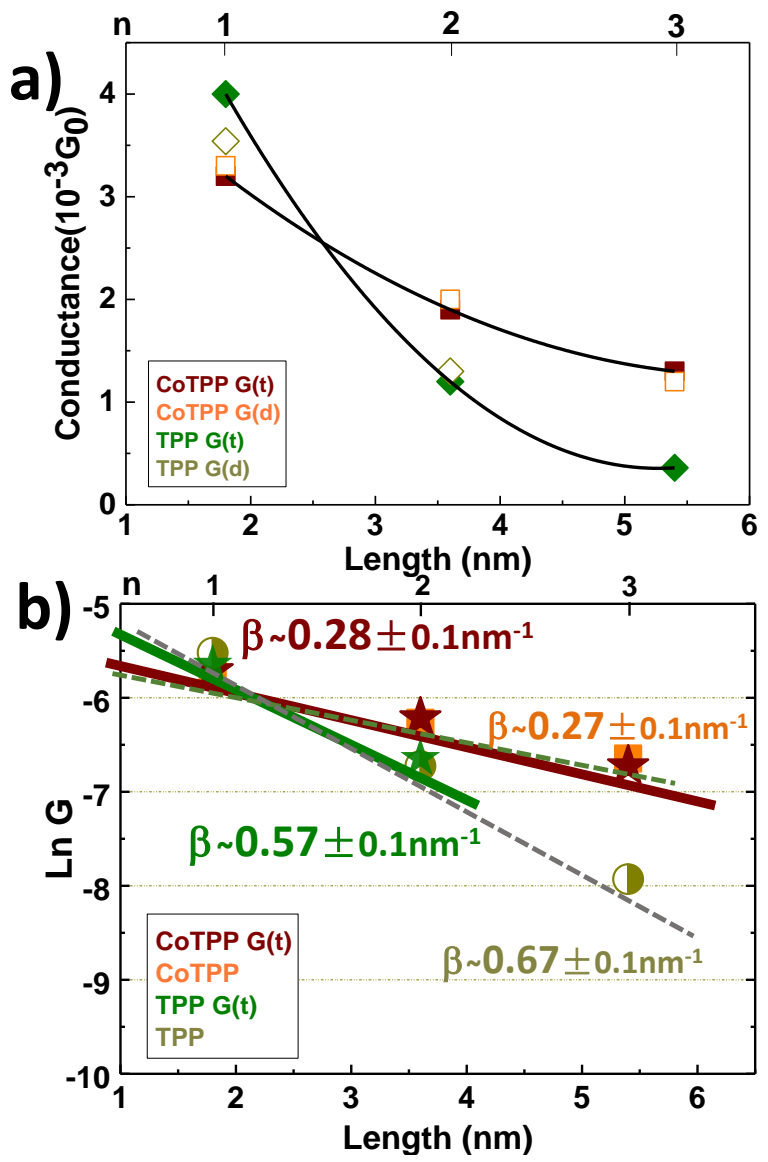

Figure 5. (a) Au-[CoTPP $]_{n}-A u$ and Au-[TPP $]_{n}-A u$ SMJs conductance decay with junction length (b) same data in Ln scale Attenuation plots vs. thickness are indicated for the two molecules in red and green, respectively. The plain lines are plotted from the $\mathrm{G}_{\text {Time }}$ values shown in Figure 4 while the dotted lines are from the $\mathrm{G}_{\text {Histo }}$ in Figure 2.

Attenuation plots (or $\beta$ plots) reflect the transport mechanisms from the conductance dependence on the molecular junction length. ${ }^{15,17,40-42,83,84}$ Figure 5a shows that both the $\mathrm{Au}-[\mathrm{CoTPP}]_{\mathrm{n}}-\mathrm{Au}$ and the Au-[TPP $]_{\mathrm{n}}-\mathrm{Au}$ SMJs show non-linear conductance decay with junction length. The $\mathrm{Au}-[\mathrm{TPP}]_{\mathrm{n}}-\mathrm{Au}$ SMJs conductance values decay faster than those of the CoTPP SMJ. $\beta$ plots for the Au-[CoTPP $]_{n}-A u$ and Au-[TPP $]_{n}$ Au SMJs ( $n=1,2,3)$ measured from the STM-bj histograms ( $\mathrm{G}_{\text {Histo, }}$ red dotted plot) are given in Figure $5 \mathrm{~b}$. For the Au[CoTPP $]_{\mathrm{n}}-\mathrm{Au}$ SMJs, a $\beta$ value of $0.27 \pm 0.1 \mathrm{~nm}^{-1}$ is obtained while a value of $0.67 \pm 0.1 \mathrm{~nm}^{-1}$ is found for Au-[TPP $]_{\mathrm{n}}-A u$ SMJs (green dotted plot in Figure $5 \mathrm{~b}$ ). These values are much smaller than those observed with $\mathrm{1D}$ conjugated molecules in the non-resonant tunneling regime (thickness below $5 \mathrm{~nm}$ ) but are close to those already observed for porphyrin-based molecular nanowires. 77-79,85 The lower sensitivity of the con- ductance of Au-[CoTPP $]_{\mathrm{n}}-\mathrm{Au} \mathrm{SMJ}$ s to junction length (from 2 to $5.5 \pm 1 \mathrm{~nm}$ ) indicates that (i) while the dominant transport mechanism for Au-[TPP $]_{n}$-Au SMJs is still most probably nonresonant tunneling, that for $\mathrm{Au}-[\mathrm{CoTPP}]_{\mathrm{n}}-\mathrm{Au} \mathrm{SMJs}$ is closer to resonant tunneling with some contribution from redox hopping (the temperature effect on the transport properties of $\mathrm{Au}-[\mathrm{CoTPP}]_{\mathrm{n}}-\mathrm{Au} \mathrm{SMJs}$ is beyond the scope of this study); (ii) there is a strong signature of the cobalt center on the electronic transport properties at the single molecule level. This last effect can be explained in several ways but the most straightforward one is that $\beta$, in the simple Simmons model, 86 decreases with the square root of the gap between the Fermi level of the electrodes and the molecular orbital involved in transport. The fact that the HOMO of the CoTPP is closer to the Fermi level of the bottom gold electrode than that of the free base explains, qualitatively, the difference in the $\beta$ values.

More importantly, the $\beta$ values can thus be obtained from both the $\mathrm{G}_{\text {Histo }}$ (dotted plot in Figure $5 \mathrm{~b}$ ) and the $\mathrm{G}_{\text {Time }}$ values (plain plot in Figure $5 \mathrm{~b}$ ). To the best of our knowledge, due to the instability of SMJs in previous work, such attenuation plots from the two methods have never been reported and compared elsewhere. Here, $\beta$ values of $0.28 \pm 0.1 \mathrm{~nm}^{-1}$ and $0.57 \pm 0.1 \mathrm{~nm}^{-1}$ are found for the first time from $\mathrm{G}_{\text {Time }}$ vs. length plots for $\mathrm{Au}-[\mathrm{CoTPP}]_{\mathrm{n}}-\mathrm{Au}$ and $\mathrm{Au}-[\mathrm{TPP}]_{\mathrm{n}}-\mathrm{Au} \mathrm{SMJs}$, respectively. The results are very similar to those obtained from $\mathrm{G}_{\text {Histo }}$ (dotted plot in Figure $5 \mathrm{~b}$ ).

Overall, we have fabricated SMJs from two different porphyrins (CoTPP and TPP freebase) oligomers with junction lengths varying from $1.8,3.6$ to $5.5 \pm 0.5 \mathrm{~nm}$. In contrast to many SMJ studies the molecules used are not in solution but are first organized in layers of controlled thickness using diazonium reduction. SMJ conductances have been characterized by the STM-bj technique and SMJ stability was investigated by conductance versus time $(\mathrm{G}(\mathrm{t}))$ measurements. The $\mathrm{Au}-[\mathrm{CoTPP}]_{\mathrm{n}}-\mathrm{Au} \mathrm{SMJs}$ have high conductance values $\left(10^{-3} \mathrm{G}_{\mathrm{o}}\right)$ which fall slowly ( $\beta$ around $0.3 \mathrm{~nm}^{-1}$ ) with increasing junction length. The conductance of $\mathrm{Au}-[\mathrm{TPP}]_{\mathrm{n}} \mathrm{Au} \mathrm{SMJs}$ falls faster (from $10^{-3}$ to $10^{-4} \mathrm{G}_{\mathrm{o}}$ ) with the junction length and $\beta$ is around $0.6 \mathrm{~nm}^{-1}$. More importantly, it is found that the diazoniumbased deposition method generates robust and compact layers which allow the fabrication of SMJs with unprecedented stability. Au-[CoTPP]1-Au SMJ blinking is first observed with random telegraph $\mathrm{G}(\mathrm{t})$ signals, indicating ON/OFF junction formation. The SMJ then stabilizes and exhibits a surprisingly long lifetime, lasting up to around $8 \mathrm{~s}$ before partial breakdown. Moreover, taking advantage of the high stability of the junction, we have obtained $\mathrm{G}(\mathrm{t})$ curves for Au$[\mathrm{CoTPP}]_{\mathrm{n}}-\mathrm{Au}$ and $\mathrm{Au}-[\mathrm{TPP}]_{\mathrm{n}}-\mathrm{Au} \mathrm{SMJs}$ of various thicknesses. It is found that the attenuation plots obtained from the STMbj histograms and the $G(t)$ curves are almost identical. This clearly indicates that the time-average for one long-lived SMJ 
and the average for many SMJs with short lifetimes are here similar.

This work shows that diazonium grafting is very effective for building highly stable SMJs and may allow improved characterizations of the transport properties through various molecular systems at the single-molecule level.

\section{METHODS SECTION}

Equipments for electrochemical experiments were described in a previous publication. 57 The diazonium derivatives of the amino-porphyrin derivatives were generated in-situ and were then reduced by sweeping the potential of the gold electrode between $0.5 \mathrm{~V}$ or $0.1 \mathrm{~V} / \mathrm{SCE}$ and various final potentials for a riable number of scans (Table $\mathrm{S}$ ). Before grafting, the solutions were deoxygenated by bubbling argon for at least $15 \mathrm{~min}$. After each grafting, the modified electrodes were copiously rinsed in an acetonitrile solution to remove all physisorbed molecules from the deposited layers. AFM measurements were performed using a Nano-Observer AFM microscope (CSInstruments AFM Microscopes, France). Images were recorded in the tapping mode with a tip from Budgetsensor (AFM tap $300 \mathrm{G}$, resonance frequency $300 \mathrm{kHz}$, force constant $40 \mathrm{nN} / \mathrm{m})$

Scanning tunneling microscopy (Molecular Imaging) is used for the fabrication of SMJ. Two different methods are employed. For the $G(d)$ measurement, the STM tip is driven into contact with the molecules on Au substrates and then pulled out to generate metal-molecule-metal junctions. The tip picks (with a certain yield) a molecule and an SMJ can be formed. During the pulling process, the Au tip is stretched into a thin gold wire where a current plateau versus distance (I(d) trace is observed. With further pulling the Au nanowire is broken the SMJ breaks down. The mechanically controlled building and breaking of the junctions allow a statistical record of $\mathrm{I}(\mathrm{d})$ traces, converted to $\mathrm{G}(\mathrm{d})$ showing conductance plateaus. The conductance of the junctions is determined by constructing a histogram from hundreds or thousands of $\mathrm{I}(\mathrm{d})$ traces with visible current plateaus. In the $\mathrm{G}(\mathrm{t})$ method, the STM tip is stabilized at a fixed distance by adjusting the initial tunneling parameters $\left(I_{t}=1 \mathrm{nA}\right.$, and $\left.U_{s}=0.02-0.05 \mathrm{~V}\right)$. These parameters are chosen so that the tip is almost in contact with the layer. The STM feedback is then turned off and the current is recorded as a molecule bridges the two electrodes, showing that an SMJ is formed, and the conductance vs. time traces are recorded.

\section{ASSOCIATED CONTENT}

Supporting Information

The Supporting Information is available free of charge. It includes details of STM-bj current traces and conductance histograms, CV curves and thickness characterization by AFM scratching.

\section{AUTHOR INFORMATION}

Corresponding Authors

*sun.xiaonan@univ-paris-diderot.fr

*lacroix@univ-paris-diderot.fr

ORCID

Xinlei Yao: oooo-0oo2-2665-5561

Maxime Vonesch: oooo-ooo1-6710-6537

Maïwenn Combes

Jean Weiss: oooo-ooo1-7753-8958

Xiaonan Sun: oooo-0003-4793-2027

Jean-Christophe Lacroix: oooo-0oo2-7024-4452

\section{ACKNOWLEDGMENT}

The Agence Nationale de la Recherche (France ANR-15-CEo9 ooo1-01, ANR-10-LABX-0o96 et ANR-18-IDEX-ooo1) and the China Scholar Council are gratefully acknowledged for their financial support. MV thanks the Université de Strasbourg for a doctoral grant. The authors thank Dr. J. S. Lomas for English editing and scientific discussion. This article is dedicated to Dr. Nongjian Tao for his great contribution in the field of single-molecule junctions.

AUTHOR CONTRIBUTIONS: XS, JW and JCL conceived and designed the experiments. MV, MC and JW carried out molecular synthesis. XY performed the device fabrication and electrical measurements. XY, XS and JCL analyzed the data and wrote the paper. All the authors discussed the results and commented on the manuscript.

\section{REFERENCES}

Liu, Y.; Li, C.; Ren, Z.; Yan, S.; Bryce, M. R. AllOrganic Thermally Activated Delayed Fluorescence Materials for Organic Light-Emitting Diodes. Nat. Rev. Mater. 2018, 3 (4), 18020.

Zhang, Q.-C.; Xiao, H.; Zhang, X.; Xu, L.-J.; Chen, Z.N. Luminescent Oligonuclear Metal Complexes and the Use in Organic Light-Emitting Diodes. Coord. Chem. Rev. 2019, 378, 121-133. 

Chem. Rev. 2016, 116 (7), 4318-4440.

McCreery, R. L.; Yan, H.; Bergren, A. J. A Critical Perspective on Molecular Electronic Junctions: There Is Plenty of Room in the Middle. Phys. Chem. Chem. Phys. 2013, 15 (4), 1065-1081.

(5) Metzger, R. M. Unimolecular Electronics. Chem. Rev. 2015, 115 (11), 5056-5115.

(6) Vilan, A.; Aswal, D.; Cahen, D. Large-Area, Ensemble Molecular Electronics: Motivation and Challenges. Chem. Rev. 2017, 117 (5), 4248-4286.

(7) Lacroix, J. C. Electrochemistry Does the Impossible: Robust and Reliable Large Area Molecular Junctions. Curr. Opin. Electrochem. 2018, 7, 153-160.

(10) Tefashe, U. M.; Nguyen, Q. Van; Lafolet, F.; Lacroix, J.C.; McCreery, R. L. Robust Bipolar Light Emission and Charge Transport in Symmetric Molecular Junctions. $J$. Am. Chem. Soc. 2017, 139 (22), 7436-7439.

(11) Bayat, A.; Lacroix, J. C.; McCreery, R. L. Control of Electronic Symmetry and Rectification through Energy Level Variations in Bilayer Molecular Junctions. J. Am. Chem. Soc. 2016, 138 (37), 12287-12296.

(12) Chiechi, R. C.; Weiss, E. A.; Dickey, M. D.; Whitesides, G. M. Eutectic Gallium-Indium (EGaIn): A Moldable Liquid Metal for Electrical Characterization of SelfAssembled Monolayers. Angew. Chem. Int. Ed. 2008, 47 (1), 142-144.

(13) Bonifas, A. P.; McCreery, R. L. Soft Au, Pt and Cu Contacts for Molecular Junctions through SurfaceDiffusion-Mediated Deposition. Nat. Nanotechnol. 2010, 5 (8), 612-617.

(14) Martin, P.; Della Rocca, M. L.; Anthore, A.; Lafarge, P.; Lacroix, J.-C. Organic Electrodes Based on Grafted Oligothiophene Units in Ultrathin, Large-Area Molecular Junctions. J. Am. Chem. Soc. 2012, 134 (1), 154-157.

(15) Yan, H.; Bergren, A. J.; McCreery, R.; Della Rocca, M. L.; Martin, P.; Lafarge, P.; Lacroix, J. C. Activationless Charge Transport across 4.5 to $22 \mathrm{Nm}$ in Molecular Electronic Junctions. Proc. Natl. Acad. Sci. U. S. A. 2013, 110 (14), 5326-5330.

(16) Nguyen, Q. Van; Martin, P.; Frath, D.; Della Rocca, M. L.; Lafolet, F.; Bellinck, S.; Lafarge, P.; Lacroix, J. C. Highly Efficient Long-Range Electron Transport in a Viologen-Based Molecular Junction. J. Am. Chem. Soc. 2018, 140 (32), 10131-10134.
Nguyen, Q. Van; Tefashe, U.; Martin, P.; Della Rocca, M. L.; Lafolet, F.; Lafarge, P.; McCreery, R. L.; Lacroix, J.-C. Molecular Signature and Activationless Transport in Cobalt-Terpyridine-Based Molecular Junctions. $A d v$. Electron. Mater. 2020, 6 (7), 1901416.

(18) Yuan, L.; Wang, L.; Garrigues, A. R.; Jiang, L.; Annadata, H. V.; Anguera Antonana, M.; Barco, E.; Nijhuis, C. A. Transition from Direct to Inverted Charge Transport Marcus Regions in Molecular Junctions via Molecular Orbital Gating. Nat. Nanotechnol. 2018, 13 (4), 322-329.

Han, Y.; Nickle, C.; Zhang, Z.; Astier, H. P. A. G.; Duffin, T. J.; Qi, D.; Wang, Z.; del Barco, E.; Thompson, D.; Nijhuis, C. A. Electric-Field-Driven Dual-Functional Molecular Switches in Tunnel Junctions. Nat. Mater. 2020, 19, 843-848.

Chen, X.; Roemer, M.; Yuan, L.; Du, W.; Thompson, D.; del Barco, E.; Nijhuis, C. A. Molecular Diodes with Rectification Ratios Exceeding 105 Driven by Electrostatic Interactions. Nat. Nanotechnol. 2017, 12 (8), 797-803.

(21) Nguyen, Q. van; Martin, P.; Frath, D.; Della Rocca, M. L.; Lafolet, F.; Barraud, C.; Lafarge, P.; Mukundan, V.; James, D.; McCreery, R. L.; et al. Control of Rectification in Molecular Junctions: Contact Effects and Molecular Signature. J. Am. Chem. Soc. 2017, 139 (34), 11913-11922.

(22) Hnid, I.; Frath, D.; Lafolet, F.; Sun, X.; Lacroix, J.-C. Highly Efficient Photoswitch in Diarylethene-Based Molecular Junctions. J. Am. Chem. Soc. 2020, 142 (17), 7732-7736.

(23) Goswami, S.; Rath, S. P.; Thompson, D.; Hedström, S.; Annamalai, M.; Pramanick, R.; Ilic, B. R.; Sarkar, S.; Hooda, S.; Nijhuis, C. A.; et al. Charge Disproportionate Molecular Redox for Discrete Memristive and Memcapacitive Switching. Nat. Nanotechnol. 2020, 15 (5), 380-389.

(24) Nichols, R. J.; Haiss, W.; Higgins, S. J.; Leary, E.; Martin, S.; Bethell, D. The Experimental Determination of the Conductance of Single Molecules. Phys. Chem. Chem. Phys. 2010, 12 (12), 2801-2815.

Xin, N.; Guan, J.; Zhou, C.; Chen, X.; Gu, C.; Li, Y.; Ratner, M. A.; Nitzan, A.; Stoddart, J. F.; Guo, X. Concepts in the Design and Engineering of SingleMolecule Electronic Devices. Nat. Rev. Phys. 2019, 1, 211-230.

(26) Xu, B.; Tao, N. J. Measurement of Single-Molecule Resistance by Repeated Formation of Molecular Junctions. Science 2003, 301 (5637), 1221-1223.

Li, Y.; Buerkle, M.; Li, G.; Rostamian, A.; Wang, H.; Wang, Z.; Bowler, D. R.; Miyazaki, T.; Xiang, L.; Asai, Y.; et al. Gate Controlling of Quantum Interference and Direct Observation of Anti-Resonnances in Single Molecule Charge Transport. Nat. Mater. 2019, 18, 357- 
363.

Starr, R. L.; Fu, T.; Doud, E. A.; Stone, I.; Roy, X.; Venkataraman, L. Gold - Carbon Contacts from Oxidative Addition of Aryl Iodides. J. Am. Chem. Soc. 2020, 142 (15), 7128-7133.

(29) Peiris, C. R.; Vogel, Y. B.; Le Brun, A. P.; Aragonès, A. C.; Coote, M. L.; Díez-Pérez, I.; Ciampi, S.; Darwish, N. Metal-Single-Molecule-Semiconductor Junctions Formed by a Radical Reaction Bridging Gold and Silicon Electrodes. J. Am. Chem. Soc. 2019, 141 (37), 14788 14797.

(30) Chen, L.; Zheng, J.; Liu, J.; Gong, X.; Chen, Z.; Guo, R.; Huang, X.; Zhang, Y.; Zhang, L.; Li, R.; et al. Nonadditive Transport in Multi-Channel SingleMolecule Circuits. Small 2020, 16 (39), 2002808.

(31) Li, Z.; Smeu, M.; Park, T. H.; Rawson, J.; Xing, Y.; Therien, M. J.; Ratner, M. A.; Borguet, E. HapticityDependent Charge Transport through CarbodithioateTerminated [5,15-Bis(Phenylethynyl)Porphinato]Zinc(II) Complexes in Metal-Molecule-Metal Junctions. Nano Lett. 2014, 14 (10), 5493-5499.

(32) Muller, C. J.; Van Ruitenbeek, J. M.; De Jongh, L. J. Conductance and Supercurrent Discontinuities in Atomic-Scale Metallic Constrictions of Variable Width. Phys. Rev. Lett. 1992, 69 (1), 140.

(33) Zhou, C.; Muller, C. J.; Deshpande, M. R.; Sleight, J. W.; Reed, M. A. Microfabrication of a Mechanically Controllable Break Junction in Silicon. Appl. Phys. Lett. 1995, 67 (8), 1160-1162.

(34) Reed, M. A.; Zhou, C.; Muller, C. J.; Burgin, T. P.; Tour, J. M. Conductance of a Molecular Junction. Science (80). 1997, 278 (5336), $252 \mathrm{LP}-254$

(35) Martin, C. A.; Ding, D.; Sørensen, J. K.; Bjørnholm, T.; van Ruitenbeek, J. M.; van der Zant, H. S. J. FullereneBased Anchoring Groups for Molecular Electronics. $J$. Am. Chem. Soc. 2008, 130 (40), 13198-13199.

(36) Konishi, T.; Kiguchi, M.; Takase, M.; Nagasawa, F.; Nabika, H.; Ikeda, K.; Uosaki, K.; Ueno, K.; Misawa, H.; Murakoshi, K. Single Molecule Dynamics at a Mechanically Controllable Break Junction in Solution at Room Temperature. J. Am. Chem. Soc. 2013, 135 (3), $1009-1014$.

(37) El Abbassi, M.; Sangtarash, S.; Liu, X.; Perrin, M. L.; Braun, O.; Lambert, C.; van der Zant, H. S. J.; Yitzchaik, S.; Decurtins, S.; Liu, S. X.; et al. Robust GrapheneBased Molecular Devices. Nat. Nanotechnol. 2019, 14 (10), 957-961.

(38) Zhou, C.; Li, X.; Gong, Z.; Jia, C.; Lin, Y.; Zhong, Y.; Yang, J.; Guo, X.; Gu, C.; He, G. Direct Observation of Single-Molecule Hydrogen-Bond Dynamics with SingleBond Resolution. Nat. Commun. 2018, 9, 807.

(39) Guan, J.; Jia, C.; Li, Y.; Liu, Z.; Wang, J.; Yang, Z.; Gu, C.; Su, D.; Houk, K. N.; Zhang, D.; et al. Direct Single-
Molecule Dynamic Detection of Chemical Reactions. Sci. Adv. 2018, 4 (2), 1-9.

Li, X.; He, J.; Hihath, J.; Xu, B.; Lindsay, S. M.; Tao, N. Conductance of Single Alkanedithiols: Conduction Mechanism and Effect of Molecule- Electrode Contacts. J. Am. Chem. Soc. 2006, 128 (6), 2135-2141.

Su, T. A.; Li, H.; Klausen, R. S.; Kim, N. T.; Neupane, M.; Leighton, J. L.; Steigerwald, M. L.; Venkataraman, L.; Nuckolls, C. Silane and Germane Molecular Electronics. Acc. Chem. Res. 2017, 50 (4), 1088-1095.

He, J.; Chen, F.; Li, J.; Sankey, O. F.; Terazono, Y.; Herrero, C.; Gust, D.; Moore, T. A.; Moore, A. L.; Lindsay, S. M. Electronic Decay Constant of Carotenoid Polyenes from Single-Molecule Measurements. J. Am. Chem. Soc. 2005, 127 (5), 1384-1385.

Capozzi, B.; Dell, E. J.; Berkelbach, T. C.; Reichman, D. R.; Venkataraman, L.; Campos, L. M. Length-Dependent Conductance of Oligothiophenes. J. Am. Chem. Soc. 2014, 136 (29), 10486-10492.

Liu, Z. F.; Wei, S.; Yoon, H.; Adak, O.; Ponce, I.; Jiang, Y.; Jang, W. D.; Campos, L. M.; Venkataraman, L.; Neaton, J. B. Control of Single-Molecule Junction Conductance of Porphyrins via a Transition-Metal Center. Nano Lett. 2014, 14 (9), 5365-5370.

Sedghi, G.; García-Suárez, V. M.; Esdaile, L. J.; Anderson, H. L.; Lambert, C. J.; Martín, S.; Bethell, D.; Higgins, S. J.; Elliott, M.; Bennett, N.; et al. Long-Range Electron Tunnelling in Oligo-Porphyrin Molecular Wires. Nat. Nanotechnol. 2011, 6, 517.

(46) Yao, X.; Sun, X.; Lafolet, F.; Lacroix, J.-C. Long-Range Charge Transport in Diazonium-Based Single-Molecule Junctions. Nano Lett. 2020, 20 (9), 6899-6907.

Jia, C.; Migliore, A.; Xin, N.; Huang, S.; Wang, J.; Yang, Q.; Wang, S.; Chen, H.; Wang, D.; Feng, B.; et al. Covalently Bonded Single-Molecule Junctions with Stable and Reversible Photoswitched Conductivity. Science 2016, 352 (6292), 1443-1445.

(48) Xing, Y.; Park, T.-H.; Venkatramani, R.; Keinan, S.; Beratan, D. N.; Therien, M. J.; Borguet, E. Optimizing Single-Molecule Conductivity of Conjugated Organic Oligomers with Carbodithioate Linkers. J. Am. Chem. Soc. 2010, 132 (23), 7946-7956.

(49) Guédon, C. M.; Valkenier, H.; Markussen, T.; Thygesen, K. S.; Hummelen, J. C.; Van Der Molen, S. J. Observation of Quantum Interference in Molecular Charge Transport. Nat. Nanotechnol. 2012, 7 (5), 305309.

(50) Ismael, A. K.; Wang, K.; Al-khaykanee, M. K.; Gallagher, H. E.; Iain, M.; Lambert, C. J.; Xu, B.; Nichols, R. J.; Higgins, S. J. Side-Group-Mediated Mechanical Conductance Switching in Molecular Junctions. Angew. Chem. Int. Ed. 2017, 56 (48), 1537815382. 
Responsivity in Single-Molecule Dithienoborepin Junctions. Chem. - A Eur. J. 2019, 25 (66), 1514115146.

(52) Delamar, M.; Hitmi, R.; Pinson, J.; Savéant, J. M. Covalent Modification of Carbon Surfaces by Grafting of Functionalized Aryl Radicals Produced from Electrochemical Reduction of Diazonium Salts. J. Am. Chem. Soc. 1992, 114 (12), 5883-5884.

(53) Pinson, J.; Podvorica, F. Attachment of Organic Layers to Conductive or Semiconductive Surfaces by Reduction of Diazonium Salts. Chem. Soc. Rev. 2005, 34 (5), 429439.

(54) Stockhausen, V.; Ghilane, J.; Martin, P.; Trippe-Allard, G.; Randriamahazaka, H.; Lacroix, J.-C. Grafting Oligothiophenes on Surfaces by Diazonium Electroreduction: A Step toward Ultrathin Junction with Well-Defined Metal/Oligomer Interface. J. Am. Chem. Soc. 2009, 131 (41), 14920-14927.

(55) Luguya, R.; Jaquinod, L.; Fronczek, F. R.; Grac, M.; Smith, K. M. Synthesis and Reactions of Meso - ( p Nitrophenyl ) Porphyrins. Tetrahedron 2004, 60 (12), 2757-2763.

(56) Xue, Z.; Hou, A.; Kwong, D. W.; Wong, W. Novel Ebselen - Porphyrin Conjugates : Synthesis and Nucleic Acid Interaction Study. Bioorganic Med. Chem. Lett. 2007, 17, 4266-4270.

(57) Stockhausen, V.; Trippé-Allard, G.; Nguyen, V. Q.; Ghilane, J.; Lacroix, J. C. Grafting $\pi$-Conjugated Oligomers Incorporating 3,4-Ethylenedioxythiophene (EDOT) and Thiophene Units on Surfaces by Diazonium Electroreduction. J. Phys. Chem. C 2015, 119 (33), 19218-19227.

(58) Nguyen, Q. Van; Lafolet, F.; Martin, P.; Lacroix, J. C. Ultrathin Molecular Layer Junctions Based on Cyclometalated Ruthenium Complexes. J. Phys. Chem. C 2018, 122 (50), 29069-29074.

(59) Jousselme, B.; Bidan, G.; Billon, M.; Goyer, C.; Kervella, Y.; Guillerez, S.; Hamad, E. A.; Goze-Bac, C.; Mevellec, J.-Y. Y.; Lefrant, S. One-Step Electrochemical Modification of Carbon Nanotubes by Ruthenium Complexes via New Diazonium Salts. J. Electroanal. Chem. 2008, 621 (2), 277-285.

(60) Anariba, F.; DuVall, S. H.; McCreery, R. L. Mono- and Multilayer Formation by Diazonium Reduction on Carbon Surfaces Monitored with Atomic Force Microscopy "Scratching." Anal. Chem. 2003, 75 (15), 3837-3844.

(61) Brooksby, P. A.; Downard, A. J. Electrochemical and Atomic Force Microscopy Study of Carbon Surface Modification via Diazonium Reduction in Aqueous and Acetonitrile Solutions. Langmuir 2004, 20 (12), 5038-

5045

Greenwood, J.; Phan, T. H.; Fujita, Y.; Li, Z.; Ivasenko, O.; Vanderlinden, W.; Van Gorp, H.; Frederickx, W.; Lu, G.; Tahara, K.; et al. Covalent Modification of Graphene and Graphite Using Diazonium Chemistry: Tunable Grafting and Nanomanipulation. ACS Nano 2015, 9 (5), 5520-5535.

(63) Pla-Vilanova, P.; Aragonès, A. C.; Ciampi, S.; Sanz, F.; Darwish, N.; Diez-Perez, I. The Spontaneous Formation of Single-Molecule Junctions via Terminal Alkynes. Nanotechnology 2015, 26 (38), 381001.

(64) Aragonès, A. C.; Darwish, N.; Ciampi, S.; Sanz, F.; Gooding, J. J.; Díez-Pérez, I. Single-Molecule Electrical Contacts on Silicon Electrodes under Ambient Conditions. Nat. Commun. 2017, 8 (1), 15056.

(65) Afsari, S.; Li, Z.; Borguet, E. Orientation-Controlled Single-Molecule Junctions. Angew. Chem. Int. Ed. 2014, 53 (37), 9771-9774.

(66) Inkpen, M. S.; Lemmer, M.; Fitzpatrick, N.; Milan, D C.; Nichols, R. J.; Long, N. J.; Albrecht, T. New Insights into Single-Molecule Junctions Using a Robust, Unsupervised Approach to Data Collection and Analysis. J. Am. Chem. Soc. 2015, 137 (31), 9971-9981.

(67) Huang, F.; Li, R.; Wang, G.; Zheng, J.; Tang, Y.; Liu, J.; Yang, Y.; Yao, Y.; Shi, J.; Hong, W. Automatic Classification of Single-Molecule Charge Transport Data with an Unsupervised Machine-Learning Algorithm. Phys. Chem. Chem. Phys. 2020, 22 (3), 1674-1681.

(68) Kamenetska, M.; Quek, S. Y.; Whalley, A. C.; Steigerwald, M. L.; Choi, H. J.; Louie, S. G.; Nuckolls, C.; Hybertsen, M. S.; Neaton, J. B.; Venkataraman, L. Conductance and Geometry of Pyridine-Linked SingleMolecule Junctions. J. Am. Chem. Soc. 2010, 132 (19), $6817-6821$.

Chen, F.; Li, X.; Hihath, J.; Huang, Z.; Tao, N. Effect of Anchoring Groups on Single-Molecule Conductance: Comparative Study of Thiol-, Amine-, and CarboxylicAcid-Terminated Molecules. J. Am. Chem. Soc. 2006, 128 (49), 15874-15881.

(70) Kamenetska, M.; Koentopp, M.; Whalley, A. C.; Park, Y. S.; Steigerwald, M. L.; Nuckolls, C.; Hybertsen, M. S.; Venkataraman, L. Formation and Evolution of Single-Molecule Junctions. Phys. Rev. Lett. 2009, 102 (12), 2-5.

Venkataraman, L.; Klare, J. E.; Tam, I. W.; Nuckolls, C.; Hybertsen, M. S.; Steigerwald, M. L. Single-Molecule Circuits with Well-Defined Molecular Conductance. Nano Lett. 2006, 6 (3), 458-462.

Iwane, M.; Fujii, S.; Nishino, T.; Kiguchi, M. Single Tripyridyl-Triazine Molecular Junction with Multiple Binding Sites. J. Phys. Chem. C 2016, 120 (16), 89368940. 
García, L.; Sanz, F.; Puigmartí-Luis, J.; Amabilino, D. B.; Díez-Pérez, I. Highly Conductive Single-Molecule Wires with Controlled Orientation by Coordination of Metalloporphyrins. Nano Lett. 2014, 14 (8), 4751-4756.

(74) El Abbassi, M.; Zwick, P.; Rates, A.; Stefani, D.; Prescimone, A.; Mayor, M.; Van Der Zant, H. S. J.; Dulić, D. Unravelling the Conductance Path through Single-Porphyrin Junctions. Chem. Sci. 2019, 10 (36), 8299-8305.

(75) Perrin, M. L.; Prins, F.; Martin, C. A.; Shaikh, A. J.; Eelkema, R.; Esch, J. H. Van; Briza, T.; Kaplanek, R.; Kral, V.; Ruitenbeek, J. M. Van; et al. Influence of the Chemical Structure on the Stability and Conductance of Porphyrin Single-Molecule Junctions. Angew. Chem. 2011, 123, 11419-11422.

(76) Diez-Perez, I.; Hihath, J.; Hines, T.; Wang, Z.-S.; Zhou, G.; Müllen, K.; Tao, N. Controlling Single-Molecule Conductance through Lateral Coupling of $\pi$ Orbitals. Nat. Nanotechnol. 2011, 6 (4), 226-231.

(77) Díez-Pérez, I.; Hihath, J.; Lee, Y.; Yu, L.; Adamska, L.; Kozhushner, M. A.; Oleynik, I. I.; Tao, N. Rectification and Stability of a Single Molecular Diode with Controlled Orientation. Nat. Chem. 2009, 1 (October), 635-641.

(78) Haiss, W.; Nichols, R. J.; van Zalinge, H.; Higgins, S. J.; Bethell, D.; Schiffrin, D. J. Measurement of Single Molecule Conductivity Using the Spontaneous Formation of Molecular Wires. Phys. Chem. Chem. Phys. 2004, 6 (17), 4330-4337.

(79) Leary, E.; Gonzalez, M. T.; van der Pol, C.; Bryce, M. R.; Filippone, S.; Martín, N.; Rubio-Bollinger, G.; Agraï, N. Unambiguous One-Molecule Conductance Measurements under Ambient Conditions. Nano Lett. 2011, 11 (6), 2236-2241.

(80) Chang, S.; He, J.; Lin, L.; Zhang, P.; Liang, F.; Young, M.; Huang, S.; Lindsay, S. Tunnel Conductance of Watson-Crick Nucleoside-Base Pairs from Telegraph Noise. Nanotechnology 2009, 20 (18), 185102.

(81) Brunner, J.; González, M. T.; Schönenberger, C.; Calame, M. Random Telegraph Signals in Molecular Junctions. J. Phys. Condens. Matter 2014, 26 (47), 474202 .

(82) Amatore, C.; Grün, F.; Maisonhaute, E. Electrochemistry within a Limited Number of Molecules: Delineating the Fringe between Stochastic and Statistical Behavior. Angew. Chem. 2003, 115 (40), 5094-5097.

(83) Tuccitto, N.; Ferri, V.; Cavazzini, M.; Quici, S.; Zhavnerko, G.; Licciardello, A.; Rampi, M. A. Highly Conductive 40-Nm-Long Molecular Wires Assembled by Stepwise Incorporation of Metal Centres. Nat. Mater. 2009, 8 (1), 41-46.

(84) Luo, L.; Choi, S. H.; Frisbie, C. D. Probing Hopping Conduction in Conjugated Molecular Wires Connected to Metal Electrodes. Chem. Mater. 2011, 23 (3), 631-
645.

Sedghi, G.; Sawada, K.; Esdaile, L. J.; Hoffmann, M.; Anderson, H. L.; Bethell, D.; Haiss, W.; Higgins, S. J.; Nichols, R. J. Single Molecule Conductance of Porphyrin Wires with Ultralow Attenuation. J. Am. Chem. Soc. 2008, 130 (27), 8582-8583.

(86) Simmons, J. G. Generalized Formula for the Electric Tunnel Effect between Similar Electrodes Separated by a Thin Insulating Film. J. Appl. Phys. 1963, 34 (6), 17931803.

Proposed TOC

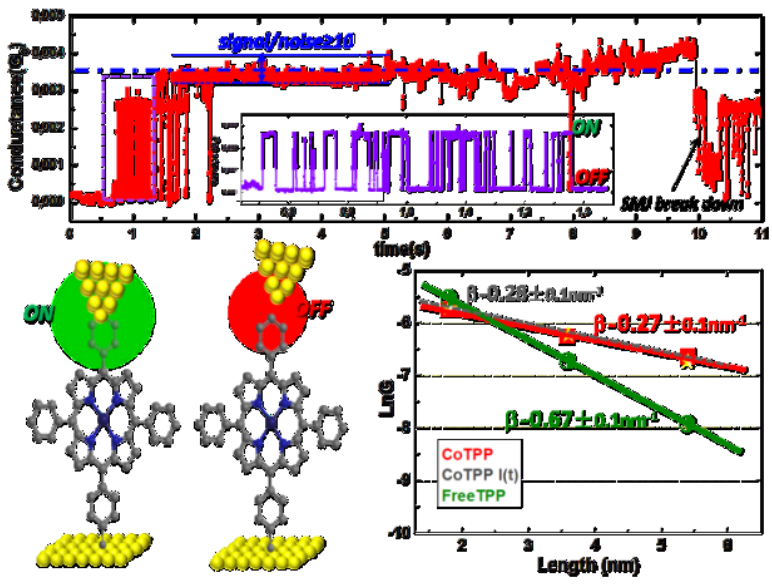


